Research Article

\title{
Ergonomic Reliability Assessment for Passenger Car Interface Design Based on EWM-MADM and Human Cognitive Reliability Experiments
}

\author{
Xin Liu $\mathbb{D}^{1},{ }^{1}$ Zheng Liu $\mathbb{D}^{2},{ }^{2}$ Jia-Tuo Chen $\mathbb{D}^{1},{ }^{1}$ Xin-Lou Yu $\mathbb{D}^{3},{ }^{3}$ Bin-Jun Lai, ${ }^{2}$ Bo Zhan, ${ }^{2}$ \\ and Sai-Fan Huang ${ }^{2}$ \\ ${ }^{1}$ Industrial Design Specialty, Guangzhou University, Guangzhou 510006, China \\ ${ }^{2}$ School of Mechanical and Electrical Engineering, Guangzhou University, Guangzhou 510006, China \\ ${ }^{3}$ Hongda Auto Parts Trading Co., Ltd., Jingdezhen, Jiangxi 333000, China
}

Correspondence should be addressed to Zheng Liu; liu_best@yeah.net

Received 27 July 2020; Revised 25 September 2020; Accepted 22 October 2020; Published 17 November 2020

Academic Editor: Grzegorz Lesiuk

Copyright $(92020$ Xin Liu et al. This is an open access article distributed under the Creative Commons Attribution License, which permits unrestricted use, distribution, and reproduction in any medium, provided the original work is properly cited.

\begin{abstract}
The ergonomic reliability assessment of interface design scheme for the passenger car is very practical to enhance driving safety performance. In addition, it can significantly reduce development costs and the development cycle of the new car. From the perspective of guiding the improvement of the central console interactive interface design of the passenger car, the most effective method to build the ergonomic reliability assessment method of the interactive interface is to evaluate and predict the human reliability objectively and subjectively and to design, feedback, and guide the design process of the ergonomic interface for the passenger car. Firstly, the questionnaire survey and the classification of ergonomic reliability analysis factors are analyzed to be put forward based on predecessors; the judgment layer factors and index layer factors of human-machine interaction interface in automobile central console are put forward. Secondly, entropy weight method (EWM) and multiple attribute decision-making (MADM) were used for objective evaluation and subjective evaluation, respectively. Thirdly, the interaction interfaces in central consoles of three different passenger cars are taken as examples; objective simulated experimental test based on entropy weight method and subjective scoring evaluation based on MADM were conducted, respectively. Besides, the objective evaluation and subjective evaluation are coupled by fuzzy comprehensive evaluation. Finally, to verify the effectiveness and rationality of the ergonomic reliability assessment method, human cognitive reliability experiments are made based on the data acquisition from the eye-tracking experiments.
\end{abstract}

\section{Introduction}

Automobile reliability is an important evaluation index of the quality of the automobile, and it is also the primary concern of users, so automobile reliability evaluation is very important [1]. The reliability of automobiles and their components is of course very crucial [2]. To some extent, it is one of the key guarantees of vehicle safety. However, the reliability of automobiles and their components is not enough, which cannot fully guarantee the safety of automobiles. During driving, user's errors may cause task failure and even lead to serious road accidents. In fact, the safety of automobiles is related not only to the reliability of automobiles and their components, but also to the reliability of drivers themselves. In other words, when a car is on the road, the reliability of the driver is also very important to ensure the safety. In addition, if the ergonomic reliability evaluation of the interactive interface of the cockpit center console is carried out after the production of the automobile, the development cost will be high and the development cycle will be long. Full consideration of the ergonomic reliability in the process of automobile design can greatly reduce the development cost and shorten the development cycle. This can improve the efficiency of automobile design and 
production. Therefore, it is very important for automobile manufacturers and users to take full account of humanmachine reliability in automobile design stage. So, how to establish a reasonable ergonomic reliability evaluation method for the interface of passenger car is very necessary. The following literatures support the research of this paper.

The reliability analysis researches field about car mainly concentrates on two aspects. Firstly, there are literatures concerning fatigue reliability $[3,4]$. The reliability assessment from the Markov process based on the fatigue life data corresponded well [5]. Using pseudoparabolic fuzzy numbers, a more realistic fuzzy reliability analysis is provided for an imprecise failure to start an automobile [6]. Secondly, with the development of reliability analysis field [7, 8], some literatures focus on the operational reliability of mechanical systems under multiple sources of uncertainty [9]. It is demonstrated that the reliability of a vehicle is very different because of its driving [10]. The reliability of an automobile crankshaft is analyzed and predicted through analyzing the time to failure [11]. A method of estimating automotive component reliability uses field warranty repair data that comprises early failure data [12].

Obviously, the existing analysis of automobile reliability focuses on deepening and expanding the methods but does not pay enough attention to the role of ergonomics which means that automobile reliability was mainly studied based on the automobile itself and its components but always ignored the driver. This paper tries to make more supplement for this knowledge.

The research of ergonomic reliability analysis method is more and more popular, and it is considered as the key research field of interdisciplinary penetration [13-17]. In recent years, there are some ergonomic reliability evaluations in the workplace for assessing working environment or for specific occupations $[18,19]$. Eye-tracking experiments are used in various fields of human cognitive reliability analysis regularly $[20,21]$. Nowadays, there are some vehicle reliability researches that mainly focused on the human actions of simulation experiments [22, 23]; different psychological tests for reliability assessment of the quality of the human being are also frequently used method in the field of vehicle design [24]. However, there are few related researches based on interface of passenger car. After the design scheme of interactive interface of automobile center console is put forward, the ergonomic reliability evaluation of interactive interface of automobile cockpit can be carried out effectively before it is put into production.

This paper presents a method to evaluate the ergonomic reliability of the cockpit interactive interface based on the design scheme. The method is also suitable for cars that have already been produced. In order to take the subjective influence of users into consideration, the entropy weight method and MADM are applied to the establishment of evaluation method. Various kinds of entropy are used in the different field of reliability and risk assessment or analysis [25]. For example, entropy combined Kriging metamodels for reliability assessment [26]. EWM is used in the risk assessment of floor water inrush [27]. MADM is also used in the reliability assessment usually [28]. MADM is often applied in subject assessment such as user activities reliability evaluation [29]. Owning to the subjective and the objective feature of ergonomic reliability, EWM combined with MADM is suitable for ergonomic reliability assessment. The entropy method can be used in the car failure detection [22]. The approach of the entropy method combined with MADM can play the role of complementary advantages [30] and the approach is always applied to solve the order of importance problem [31]. Therefore, this paper establishes a multilevel ergonomic reliability evaluation index system for the interactive interface of the automobile cockpit. EWM is used to conduct the objective human-machine reliability evaluation for the automobile cockpit [32], and MADM is used to conduct subjective preference human-machine reliability evaluation for the automobile cockpit. In addition, fuzzy mathematics is used to conduct the objective evaluation of fuzzy and difficult problems in human reliability assessment and analyze and feedback the evaluation results and guide the design process. At last, the human cognitive reliability experiments are proposed to verify the effectiveness of these reliability assessment methods.

\section{Ergonomic Reliability Assessment Method Based on EWM-MADM}

The process of the ergonomic reliability assessment is shown in Figure 1. At first, the assessment index system should be built according to the characteristics of passenger car interface. At second, the objective assessment based on EWM and the subjective assessment based on MADM are carried out owning to the perceptual and rational feature of ergonomic reliability. At last, the assessment results can be obtained.

2.1. Objective Weighting Calculation. The concept of entropy weight method (EWM) was first proposed by Shannon and Weaver (1948). According to the degree of variation of various factors, the entropy weight of each factor can be calculated by information entropy. The weight of each factor is corrected to obtain the objective weight value of each factor [27]. The weight determines the important degree of each component in system. The objective weights are determined based on Theil's entropy method according to the index variability [33]. If Theil's entropy of a certain index is smaller, it indicates that the degree of variation of the index is smaller; the greater the role it can play in the comprehensive assessment, the greater the weight is [34]. In contrast, if Theil's entropy of a certain index is greater, it indicates that the degree of variation of the index is greater; the smaller the role it can play in the comprehensive assessment, the smaller the weight is [35]. Theil's entropy is defined in 1967 by

$$
E_{i}=\frac{1}{n} \sum_{i=1}^{n} \frac{a_{i j}}{\bar{a}} \log \frac{a_{i j}}{\bar{a}} .
$$

It is a special kind of generalized entropy measures [36]. The great advantage of using Theil's entropy to measure inequality is that it measures the contribution of the data in 


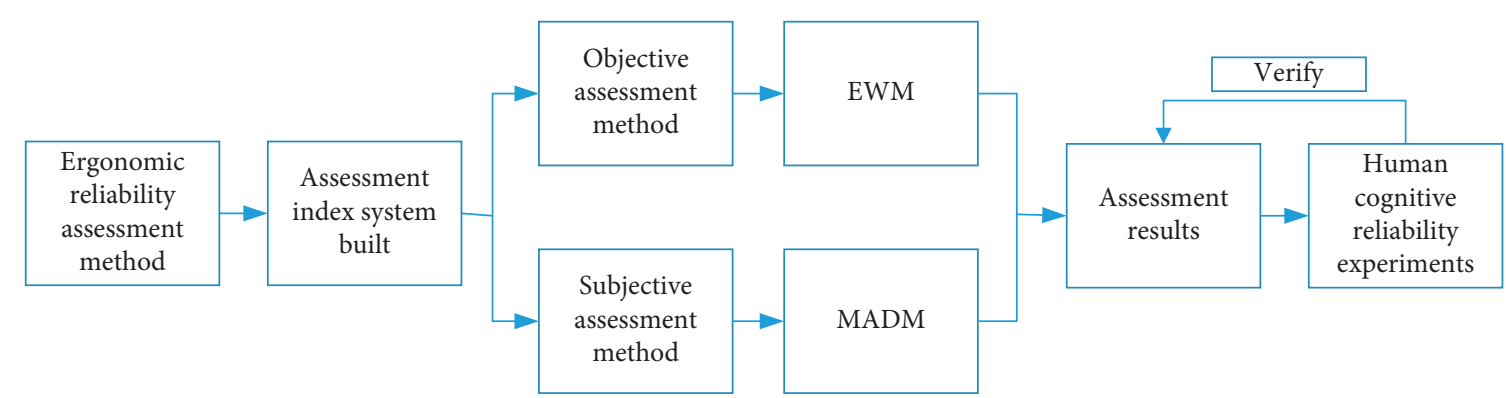

FIgURE 1: The diagram of ergonomic reliability assessment method.

the same group and with the other group to the total gap. The explanatory power of the data in the same group and with the other group on total gap is clearer, where $a_{i j}$ is the value of $i$-th index based on $j$-th participant, $n$ is the number of all factors in the index hierarchy, and $\bar{a}$ is the average value of all factors based on the participants in the index.

Owning to good decomposition characteristic of Theil's entropy, it is very suitable for calculating the weights of multilayer indexes. $E_{i}$ is separated as follows:

$$
\begin{aligned}
E_{i} & =E_{i w}+E_{i c}, \\
e_{i} & =\sum_{i=1}^{n_{m}} \frac{a_{i j}}{\sum_{j=1}^{p} a_{i j}} \log \left(n_{k} \frac{a_{i j} \sum_{j=1}^{p} a_{i j}^{h}}{a_{i j}^{h} \sum_{j=1}^{p} a_{i j}}\right), \quad(j \in p ; h \in m),
\end{aligned}
$$

where $m$ is the number of factors in the index hierarchy. $p$ represents the number of participants:

$$
\begin{aligned}
& E_{i w}=\sum_{i=1}^{m} e_{i}, \quad(i \in m), \\
& E_{i c}=\frac{a_{i j}^{1}}{\sum_{j=1}^{p} a_{i j}^{1}} \log \left(\frac{n a_{i j}^{1}}{n_{1} \sum_{j=1}^{p} a_{i j}^{1}}\right)+\frac{a_{i j}^{2}}{\sum_{j=1}^{p} a_{i j}^{2}} \log \left(\frac{n a_{i j}^{2}}{n_{2} \sum_{j=1}^{p} a_{i j}^{2}}\right)+\frac{a_{i j}^{3}}{\sum_{j=1}^{p} a_{i j}^{3}} \log \left(\frac{n a_{i j}^{3}}{n_{3} \sum_{j=1}^{p} a_{i j}^{3}}\right)+\cdots+\frac{a_{i j}^{m}}{\sum_{j=1}^{p} a_{i j}^{m}} \log \left(\frac{n a_{i j}^{m}}{n_{k} \sum_{j=1}^{p} a_{i j}^{m}}\right),
\end{aligned}
$$

where $E_{i w}$ represents the dissimilarity in the factors in the index hierarchy. $E_{i c}$ represents the dissimilarity between the factors in the index hierarchy:

$$
\begin{aligned}
f_{i} & =\frac{e_{i}}{\sum_{i=1}^{m} e_{i}}, \quad(i \in m), \\
F_{i c} & =\frac{E_{i c}}{\sum_{c=1}^{k} E_{i c}}, \quad(c \in k) .
\end{aligned}
$$

The weight of every factor in the index hierarchies is

$$
\begin{gathered}
W_{i}^{o}=\frac{1-f_{i}}{\sum_{i=1}^{m}\left(1-f_{i}\right)}, \quad(i \in m), \\
W_{c}^{o}=\frac{1-F_{i c}}{\sum_{c=1}^{k}\left(1-F_{i c}\right)}, \quad(c \in k),
\end{gathered}
$$

where $k$ is the number of factors in the criterion hierarchy. $W_{c}^{o}$ is the weight of the factor in the criterion hierarchy. $W_{i}^{o}$ is the weight of the factor in the index hierarchy.

2.2. Subjective Weighting Calculation. The subjective weights are determined by MADM. Multiattribute decision making is used to sort and compare the comprehensive attribute values of factors [37]. For example, attribute $b_{i}$ can make a small difference in attribute values of all schemes, indicating that the impact of attribute $b_{i}$ on decision-making and ranking factors is smaller; on the contrary, if attribute $b_{i}$ can make a big difference in attribute values of all schemes, the impact of attribute $b_{i}$ on decision-making and ranking factors is greater. Therefore, from the point of view of factor ranking, attributes with greater differences in factor attribute values need to be given greater weight values [38]. As for attribute $b_{i}$, the difference between factor $x_{i}$ and all other factors is expressed as $G_{j i}(w) . m$ is the number of the assessment factors in the criterion or index hierarchy, $p$ represents the number of participants as

$$
G_{j i}(\mathbf{w})=\sum_{q=1}^{p}\left|b_{j i} w_{i}-b_{q i} w_{i}\right|, \quad(j \in p, i \in m) .
$$

Make

$$
G_{i}(\mathbf{w})=\sum_{j=1}^{p} G_{j i}(w)=\sum_{j=1}^{p} \sum_{q=1}^{p}\left|b_{j i}-b_{q i}\right| w_{i}, \quad(i \in m),
$$

where $G_{i}(\mathbf{w})$ presents the total deviation of all schemes for attribute $b_{i}$. The selection of weighted vector $\mathbf{w}$ should maximize the total deviation of all attributes for all schemes. Therefore, the construction of the objective function is shown in 


$$
\max G(\mathbf{w})=\sum_{i=1}^{p} G_{j i}(w)=\sum_{i=1}^{m} \sum_{j=1}^{p} \sum_{q=1}^{p}\left|b_{j i}-b_{q i}\right| w_{i} .
$$

Thus, the weight vector $\mathbf{w}$ obtained is equivalent to the following formula:

$$
\begin{cases}\max & G(\mathbf{w})=\sum_{i=1}^{m} \sum_{j=1}^{p} \sum_{q=1}^{p}\left|b_{j i}-b_{q i}\right| w_{i}, \\ \text { s.t. } & w_{i} \geq 0, i \in m, \sum_{i=1}^{m} w_{i}^{2}=1 .\end{cases}
$$

Convert (9) into Lagrange function:

$$
L(\mathbf{w}, \xi)=\sum_{i=1}^{m} \sum_{j=1}^{p} \sum_{q=1}^{p}\left|b_{j i}-b_{q i}\right| w_{i}+\frac{1}{2} \xi\left(\sum_{i=1}^{m} w_{i}^{2}-1\right) \text {. }
$$

The partial derivative is taken and got:

$$
\left.\begin{array}{l}
\frac{\partial L}{\partial w_{i}}=\sum_{j=1}^{p} \sum_{q=1}^{p}\left|b_{j i}-b_{q i}\right|+\xi w_{i}=0, \quad(i \in m), \\
\frac{\partial L}{\partial \xi}=\sum_{i=1}^{m} w_{i}^{2}-1=0 .
\end{array}\right\}
$$

Get

$$
w_{i}^{*}=\frac{\sum_{j=1}^{p} \sum_{q=1}^{p}\left|b_{j i}-b_{q i}\right|}{\sqrt{\sum_{i=1}^{m}\left[\sum_{j=1}^{p} \sum_{j=1}^{p}\left|b_{j i}-b_{q i}\right|\right]^{2}}} .
$$

Normalize $w_{i}^{*}$

$$
W_{i}^{s}=\frac{w_{i}^{*}}{\sum_{i=1}^{m} w_{i}^{*}}, \quad(i \in m)
$$

2.3. Comprehensive Assessment. Based on the weight vector $W$ and membership matrix $R$ combined by fuzzy mathematics, the result of the final assessment $R=(\mathrm{r} 1, \mathrm{r} 2, \ldots, \mathrm{rt})$ can be obtained

$$
r_{j}=\frac{\sum_{j=1}^{t} r_{j i}\left(W_{i}^{o}+W_{i}^{s}\right)}{2 \times \sum_{j=1}^{t} \sum_{i=1}^{m} r_{j i}\left(W_{i}^{o}+W_{i}^{s}\right)}, \quad(j \in t),
$$

where $t$ is the number of research schemes. $W_{i}^{o}$ and $W_{i}^{s}$ are the objective and subjective weight coefficient of each factor layer, respectively, in formula (14). If the factor weights in the criterion layer are calculated, $W_{i}^{o}$ is replaced by $W_{c}^{o}$. Based on the value of $R$ vector, the results of ergonomic reliability assessment are obtained.

\section{Case Studies of Ergonomic Reliability Assessment in the Interaction Interface}

The ergonomic system is mainly controlled by human manipulation, monitoring, and inspection. Measuring the human error is the premise of automobile ergonomic reliability analysis. Human error involves many subelements, and the inducing factors of these subelements has different mechanisms. Therefore, the ergonomic reliability analysis should not only pay attention to the various characteristics of error response, but also pay attention to the overall state of human-machine automobile environment system. 22 questionnaires were received in three weeks. Based on questionnaire survey and interview from the experienced drivers in addition with some references in $[39,40]$, as shown in Table 1 , the assessment index system about interface design of passenger car is illustrated.

Types I, II, and III of passenger car for interaction interface in automobile central console are taken as examples. There are 22 participants surveyed; 12 of them have rich experiences in driving, 10 of them are beginners who have driving experiences of less than 5 years; the information of participants investigated is shown in Table 2.

After certain training, the participants controlled the 3 different simulated automobile central console, gave the scores based on the ergonomic reliability indexes, and answered the questionnaires. Based on the data from the human behavior experiments and questionnaires, the objective and subjective weights of the criterion layer can be obtained as shown in Figure 2, whereas the objective and subjective weights of the index layer can be received as shown in Figure 3. In addition, objective reliability assessment matrix of 3 different type calculated by entropy weight method is shown in Table 3 and the subjective reliability assessment matrix of 3 different type calculated by MADM is shown in Table 4.

In Figure 4, the red curves represent the objective and subjective ergonomic reliability assessment values of type I, respectively; two green curves describe the objective and subjective ergonomic reliability assessment values of type II, respectively, in addition to two black curves describing the objective and subjective ergonomic reliability assessment values of type III, respectively. The average values of positions on the green curves are obviously lower compared with those on red curves; meanwhile, they are slightly lower than those on black curves, which means that the ergonomic reliability assessment of type II is worse than that of types I and III. Based on 16, the objective reliability assessment values vector of three types is $r_{1}=(0.34691$, $0.314166,0.338923)$ and the subjective reliability assessment values vector of three types is $r_{2}=(0.337622$, $0.327527,0.332524)$, so the total of reliability assessment values vector about three types is $r=(0.684532,0.641693$, $0.671447)$; the normalization of it is $R=(0.342665,0.32122$, $0.336115)$, so, among the ergonomic reliability assessments of types I, II, and III, type I is the best one, whereas that of type II is worse than that of type III. There are some differences between experts' subjective experience and objective experience. In addition, after the subsequent experimental verification, the learning efficiency of plan I is higher than that of plans II and III, and the subjects can remember more operating controls within a shorter time, which can also verify the reliability of this method from another perspective. 
TABLE 1: Ergonomic reliability assessment index system for the interface design of passenger car.

\begin{tabular}{|c|c|c|}
\hline Targeted hierarchy & $\begin{array}{c}\text { Criterion hierarchy } \\
C^{(1)}\end{array}$ & Index hierarchy $I^{(2)}$ \\
\hline $\begin{array}{l}\text { Ergonomic reliability assessment index } \\
\text { system for the interface design of passenger } \\
\text { car }\end{array}$ & $\begin{array}{c}C_{2}{ }^{(1)} \text { memory errors } \\
C_{3}^{(1)} \text { attention } \\
\text { invalidation } \\
C_{4}{ }^{(1)} \text { perceptual } \\
\text { confusion } \\
C_{5}{ }^{(1)} \text { negligence } \\
C_{6}{ }^{(1)} \text { checking } \\
\text { mistakes } \\
C_{7}^{(1)} \text { unsafe } \\
\text { operation } \\
C_{8}^{(1)} \text { communication } \\
\text { errors }\end{array}$ & $\begin{array}{c}I_{11}{ }^{(2)} \text { semantical vagueness, } I_{12}{ }^{(2)} \text { circumscribed sight, } I_{13}{ }^{(2)} \text { bluntness } \\
\text { sight, } I_{14}{ }^{(2)} \text { optical illusion, } I_{15}{ }^{(2)} \text { time stress, and } I_{16}{ }^{(2)} \text { habitual } \\
\text { operation. } \\
I_{21}{ }^{(2)} \text { overloaded thought, } I_{22}{ }^{(2)} \text { forgetting, } I_{23}{ }^{(2)} \text { faulty memory, } I_{24}{ }^{(2)} \\
\text { attenuation intention, } I_{25}{ }^{(2)} \text { reminiscent inaccuracy, } I_{26}{ }^{(2)} \text { shortage of } \\
\text { aided memory, } I_{27}{ }^{(2)} \text { overloaded information, and } I_{28}{ }^{(2)} \\
\text { experientialism. } \\
I_{31}{ }^{(2)} \text { loaded attention, } I_{32}{ }^{(2)} \text { interferential vision, } I_{33}{ }^{(2)} \text { overladen } \\
\text { absorption, and } I_{34}{ }^{(2)} \text { flustered at a loss. } \\
I_{41}{ }^{(2)} \text { semantical vagueness, } I_{42}{ }^{(2)} \text { biased cognition, } I_{43}{ }^{(2)} \text { irrational } \\
\text { matching, } I_{44}{ }^{(2)} \text { weak visuality, and } I_{45}{ }^{(2)} \text { misunderstanding. } \\
I_{51}{ }^{(2)} \text { inadvertence, } I_{52}{ }^{(2)} \text { attenuation intention, } I_{53}{ }^{(2)} \\
\text { unconsciousness, and } I_{54}{ }^{(2)} \text { excessive confidence. } \\
\text { missed inspection, } I_{62}{ }^{(2)} \text { lack of sufficient inspection, } I_{63}{ }^{(2)} \\
I_{66}{ }^{(2)} \text { red } \\
\text { correctness checking to wrong targets, and } I_{64}{ }^{(2)} \text { wrong checking to } \\
\text { right targets. } \\
I_{71}{ }^{(2)} \text { shortage of important attention, } I_{72}{ }^{(2)} \text { improper operation, } I_{73}{ }^{(2)} \\
\text { unreasonable job procedures, } I_{74}{ }^{(2)} \text { taking emergency apparatus } \\
\text { away, } I_{75}{ }^{(2)} \text { cut corners, and } I_{76}{ }^{(2)} \text { without protection apparatus. } \\
I_{81}{ }^{(2)} \text { no communication, } I_{82}{ }^{(2)} \text { inadequate exchange of information, } \\
\text { and } I_{83}{ }^{(2)} \text { incorrect communication information. }\end{array}$ \\
\hline
\end{tabular}

TABLE 2: Information of participants investigated.

\begin{tabular}{|c|c|c|c|c|}
\hline \multicolumn{3}{|c|}{ Age } & \multirow{2}{*}{ Gender } & \multirow{2}{*}{ Driving experience } \\
\hline $18-40$ & $40-50$ & $50-75$ & & \\
\hline- & 2 & 1 & Male & Car mechanics in the old days \\
\hline - & - & 2 & Male & More than 30 years \\
\hline - & 2 & - & Male & $\begin{array}{c}\text { More than } 20 \text { years, less than } 29 \\
\text { years }\end{array}$ \\
\hline - & 2 & - & Male & $\begin{array}{c}\text { More than } 10 \text { years, less than } 19 \\
\text { years }\end{array}$ \\
\hline - & - & 1 & Male & $\begin{array}{c}\text { More than } 5 \text { years, less than } 9 \\
\text { years }\end{array}$ \\
\hline 7 & - & - & Male & Less than 5 years \\
\hline - & - & 1 & Female & $\begin{array}{c}\text { More than } 5 \text { years, less than } 9 \\
\text { years }\end{array}$ \\
\hline 3 & - & - & Female & Less than 5 years \\
\hline - & - & 1 & Female & More than 10 years \\
\hline
\end{tabular}

\section{Verification Based on Human Cognitive Reliability Experiments}

The human cognitive reliability experiments as a kind of objective evaluation method can be built and operated based on eye-tracking device, the virtual models of three types of automobile central consoles, and the multimedia interfaces devices in the three passenger cars. The eye-tracking experiment can be analyzed according to the rational data acquisition to find the perceptual mental activity, so the experimental research is used to verify the validity and effectiveness of the ergonomic reliability assessment method from a different perspective and different method.

As shown in Figure 5, hot spot plots of the participants observing the central consoles in three different passenger car models are drawn by eye-tracking device. In order to evaluate the human cognitive reliability of the three cockpits, the central console was selected for the experiment. The following is a one-way ANOVA and multiple comparisons. Coefficient of variation (CV) can be used to compare the degree of dispersion between groups. $\mathrm{CV}$ is standardized according to its mean size. Although there is no dimension, it can be objectively compared. Therefore, the coefficient of variation is the same as the extreme difference, the standard deviation, and the variance, reflecting the absolute value of the degree of data dispersion [41, 42]. Its numerical value is affected not only by the discrete degree of variable value, but also by the average level of variable value:

$$
\begin{aligned}
E_{X} & =\frac{1}{n} \sum_{i=1}^{n} x_{i}, \\
\sigma_{x} & =\sqrt{\frac{1}{n} \sum_{i=1}^{n}\left(x_{i}-E_{X}\right)^{2},} \\
V_{x} & =\frac{\sigma_{x}}{E_{X}}, \\
P_{x} & =\frac{m V_{x}}{n} .
\end{aligned}
$$

In formula (15) to formula (18), $n$ is the number of fixation points in unimportant area, $x_{i}$ is $i$-th sampling value, $E_{X}$ is the average duration of the fixation point, $\sigma_{x}$ is the standard deviation, and $V_{x}$ is the coefficient of variation. M is the total number of samples. In the course of the experiment, the more the distraction of the driver using central console is, the smaller the coefficient of variation is. In addition, the driver's attention is also shown by proportion of fixation points distribution. The more focus points are on 


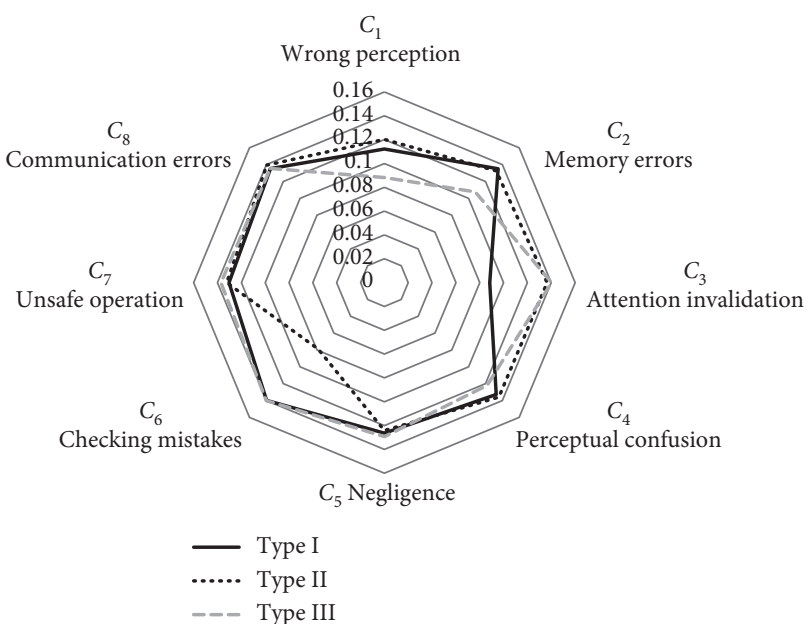

(a)

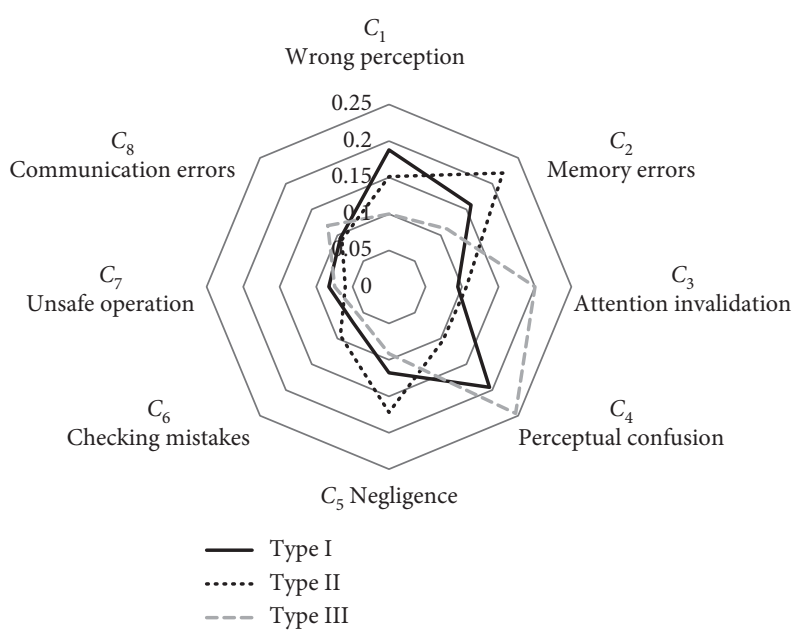

(b)

FIgURE 2: The indicator weights of the criterion hierarchy. (a) The objective weights of the criterion hierarchy. (b) The subjective weights of the criterion hierarchy.
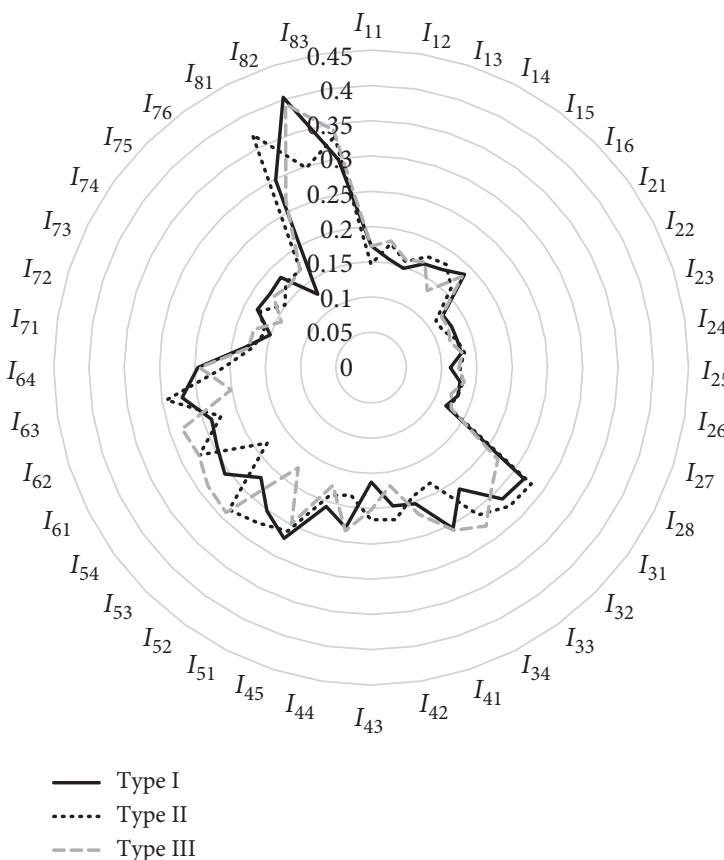

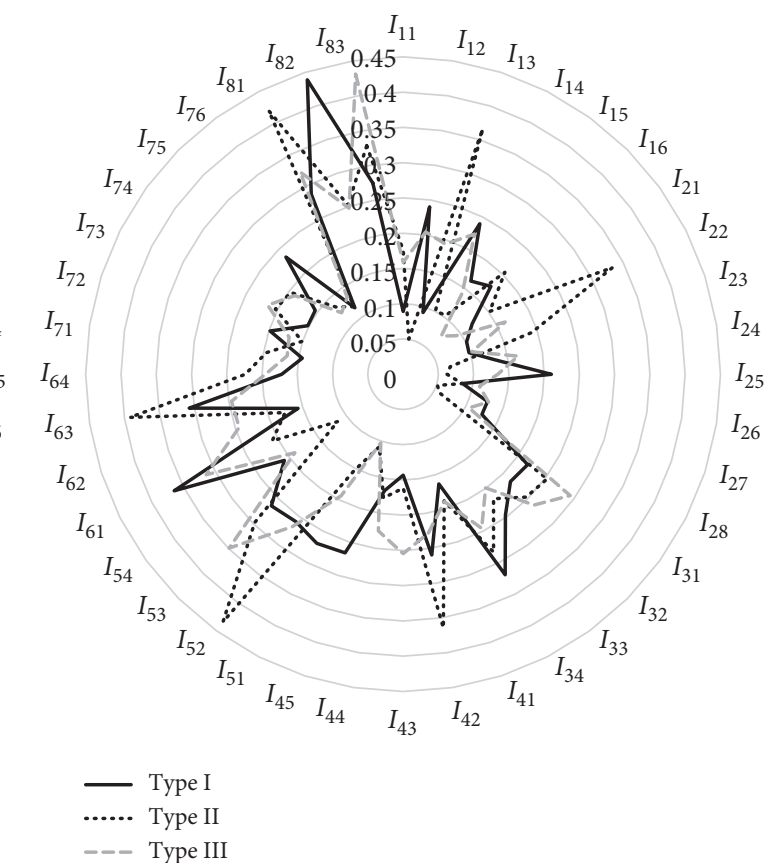

(b)

Figure 3: The indicator weights of the index hierarchy. (a) The objective weights of the index hierarchy. (b) The subjective weights of the index hierarchy.

TABle 3: Objective reliability assessment matrix of types I, II, and III obtained by entropy.

\begin{tabular}{lcccccccc}
\hline Type & $\begin{array}{c}\text { C1 wrong } \\
\text { perception }\end{array}$ & $\begin{array}{c}\text { C2 memory } \\
\text { errors }\end{array}$ & $\begin{array}{c}\text { C3 attention } \\
\text { invalidation }\end{array}$ & $\begin{array}{c}\text { C4 perceptual } \\
\text { confusion }\end{array}$ & $\begin{array}{c}C_{5} \\
\text { negligence }\end{array}$ & $\begin{array}{c}C_{6} \text { checking } \\
\text { mistakes }\end{array}$ & $\begin{array}{c}C_{7} \text { unsafe } \\
\text { operation }\end{array}$ & $\begin{array}{c}C_{8} \text { communication } \\
\text { errors }\end{array}$ \\
\hline I & 0.345932 & 0.329732 & 0.399071 & 0.343936 & 0.434908 & 0.308443 & 0.315111 & 0.29674 \\
II & 0.289565 & 0.288379 & 0.242416 & 0.329992 & 0.295627 & 0.412185 & 0.319321 & 0.341539 \\
III & 0.364503 & 0.381889 & 0.358514 & 0.326072 & 0.269465 & 0.279372 & 0.365568 & 0.361722 \\
\hline
\end{tabular}


TABLE 4: Subjective reliability assessment matrix of types I, II, and III obtained by MADM.

\begin{tabular}{lcccccccc}
\hline Type & $\begin{array}{c}C_{1} \text { wrong } \\
\text { perception }\end{array}$ & $\begin{array}{c}C_{2} \text { memory } \\
\text { errors }\end{array}$ & $\begin{array}{c}C_{3} \text { attention } \\
\text { invalidation }\end{array}$ & $\begin{array}{c}C_{4} \text { perceptual } \\
\text { confusion }\end{array}$ & $\begin{array}{c}C_{5} \\
\text { negligence }\end{array}$ & $\begin{array}{c}C_{6} \text { checking } \\
\text { mistakes }\end{array}$ & $\begin{array}{c}C_{7} \text { unsafe } \\
\text { operation }\end{array}$ & $\begin{array}{c}C_{8} \text { communication } \\
\text { errors }\end{array}$ \\
\hline I & 0.326359 & 0.354536 & 0.338501 & 0.336029 & 0.338763 & 0.344107 & 0.332517 & 0.332934 \\
II & 0.327428 & 0.317198 & 0.33365 & 0.333375 & 0.333067 & 0.324464 & 0.335603 & 0.325912 \\
III & 0.346213 & 0.328265 & 0.32785 & 0.330596 & 0.32817 & 0.331429 & 0.331879 & 0.341154 \\
\hline
\end{tabular}

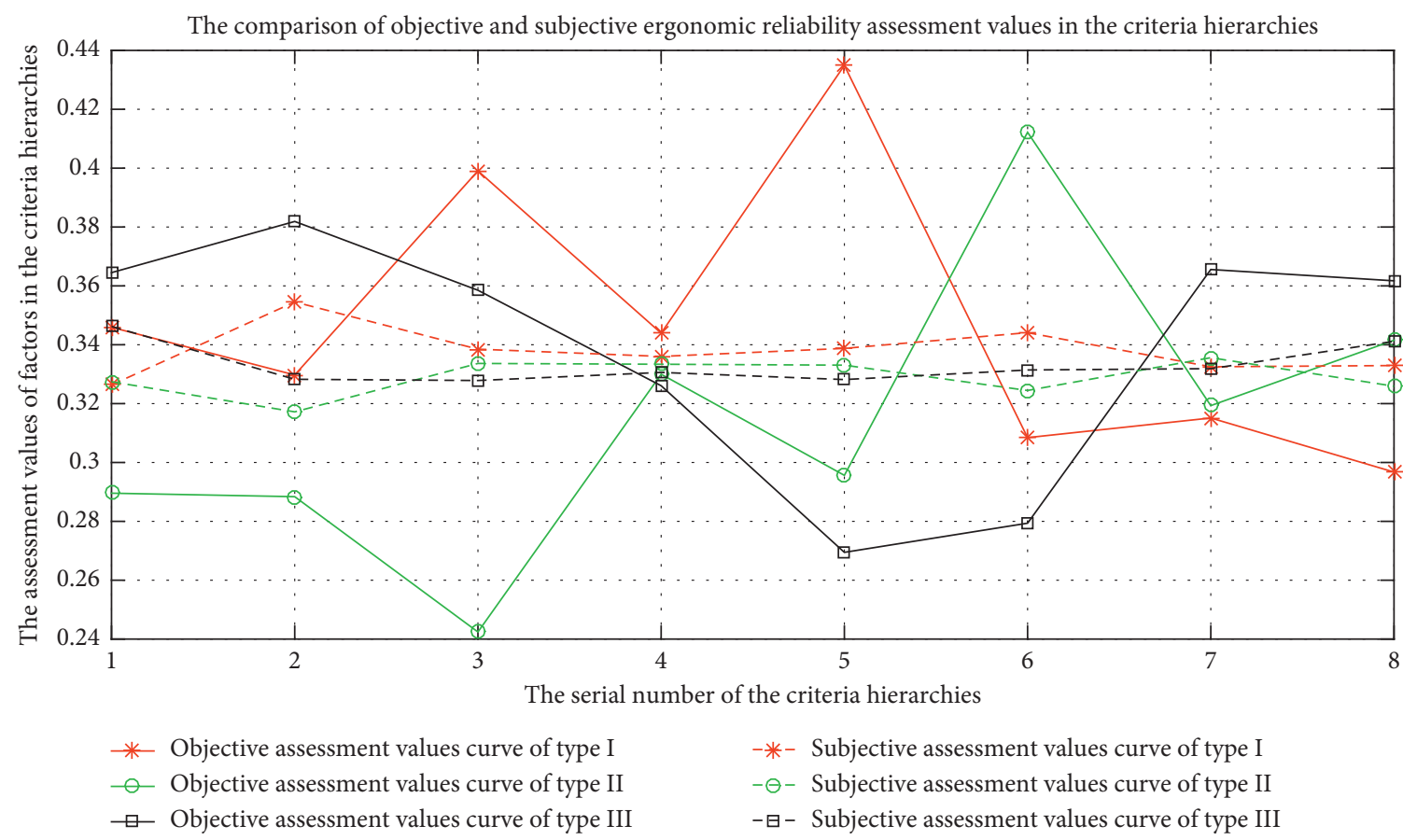

FIgURE 4: Comparison curves of ergonomic reliability assessment values in criteria hierarchy factors.

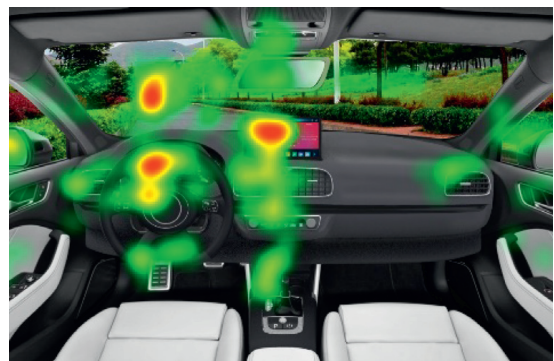

(a)

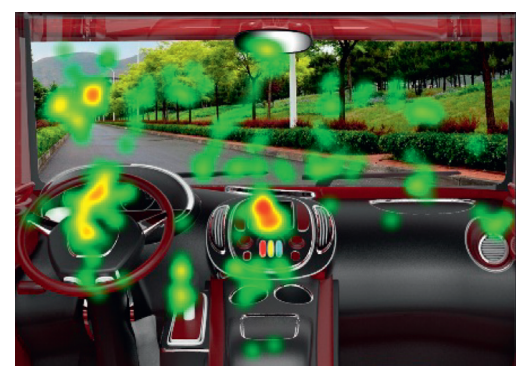

(b)

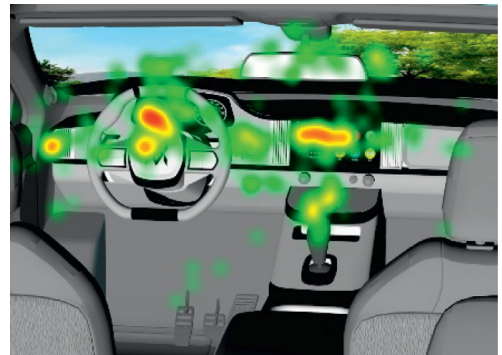

(c)

Figure 5: Hot spot plots about the three types of central consoles in passenger cars. (a) Type I. (b) Type II. (c) Type III.

important facilities which means that the bigger the values of $P_{x}$ are, the more attentive the human body is.

The variance analysis is carried out by using the coefficient of variation of the gaze point length. The variance analysis results of the gaze point length of the console in three different passenger car cockpits are given. The size of F statistic is 12.4800 . By checking the critical value table of $\mathrm{F}$ distribution, $p$ value is $0 \mathrm{E}-04$. This means rejecting the original hypothesis that the mean values of the three groups are all equal and accepting the alternative hypothesis that the mean values of the three groups are not all equal. This shows that the mean of $P_{x}$ from the three groups is different and has statistical significance. This shows that the mean of $P_{x}$ from the three groups is different and has statistical significance. In addition, Bartlett's test was used to test the homogeneity of variance, and the result was $\chi^{2}=10.6702$, and the corresponding $p=0.0050$. This indicates that the original hypothesis that the variance of all groups is equal is accepted when the test level is $1 \%$. Therefore, it is appropriate to use the experimental data for variance analysis.

In order to further analyze which of the three groups has the largest mean of coefficient of variation and which group has the smallest mean of coefficient of variation, Bonferroni 
TABle 5: Multiple comparisons of consoles for three different types of vehicles.

\begin{tabular}{lcr}
\hline A and B & $\overline{P_{A}}-\overline{P_{B}}$ & $p$ \\
\hline I and II & 1.73786 & $0 \mathrm{E}-04$ \\
I and III & 1.17482 & 0.0040 \\
III and II & 0.56303 & 0.3510 \\
\hline
\end{tabular}

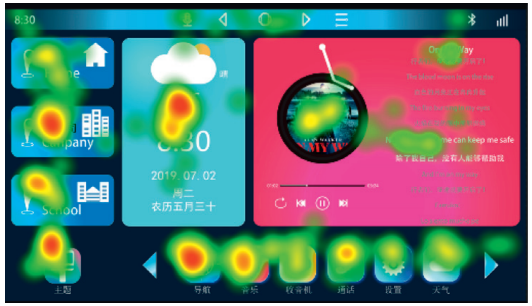

(a)

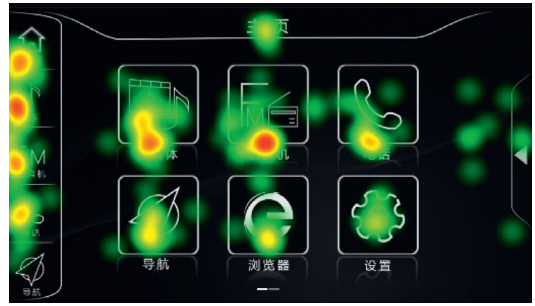

(b)

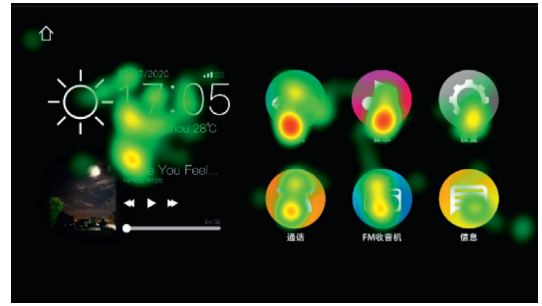

(c)

Figure 6: Eye-tracking experiments based on three types of multimedia interfaces in passenger car. (a) Type I. (b) Type II. (c) Type III.

method is used for multiple comparisons. Table 5 gives the results of multiple comparisons.

The results of multiple comparisons in Table 5 showed that the mean of group III was 0.56303 higher than that of type II and the $P$ value was 0.3510 , which indicated that there was no statistical significance. Compared with type I, the mean of type II was 1.73786 lower and the $p$ value was 0E-04, which indicated that there was statistical significance. Compared with type I, the mean of type III was 1.17482 lower and the $p$ value was 0.0040 , which indicated that there was statistical significance when the test level is $0.5 \%$. The results of multiple comparisons show that, on the whole, types II and III are harder to make people concentrate, but there is no significant difference between type II and type III. The experimental results show that the color scheme of types II and III is too colorful or bright, which may lead to the user's lack of concentration in the driving process. Type I is more focused on the important driving facilities, but the design of type II is not well designed according to the size of human body. Although the vision of cockpit of type II is wider relatively, the joystick on the right side of human body is too close to human body. The cramped space of type II leads to driving fatigue.

Because of the high frequency of the vehicle multimedia interface in the use of passenger cars, the unreasonable design of the vehicle multimedia interface is more likely to lead to the low reliability of man-machine, so the vehicle multimedia interface is put forward separately for analysis. Although the gaze time distribution of the vehicle multimedia interface is also counted during the experiment, the results are not significantly different in several groups of experiments, so they are omitted in this paper. Figure 6 shows three representative screenshots of the hot spot plots about multimedia interfaces. In Figure 6, it can be found that the icons on three kinds of multimedia interfaces have successfully attracted users' attention. During driving, the icon-style buttons of navigation and telephone systems are used with supreme frequency. In type I and type III, these two important buttons have successfully attracted more attention from users than some other less used buttons according to the hot spot plots. Because the navigation system button of type II is designed in the most inconspicuous position and the iconstyle buttons are not distinguished by different colors, the most common of navigation system button has not successfully attracted the attention of users. The design of vehicle multimedia interface in type II with the smallest size is poorer than others.

By synthesizing the analysis results of the two experiments, we can draw conclusions. The human cognitive reliability of type I is higher than that of type II and type III; In addition, after the subsequent experimental verification, the learning efficiency of type I is higher than that of types II and III, and the subjects can remember more operating controls within a shorter time, which is consistent with the analyzed results of the assessment method based on EWM-MADM. The conclusions show similar analysis results with the ergonomic reliability assessment method based on EWM-MADM to verify the validity and availability of the ergonomic reliability assessment method proposed in this research from another perspective. Ergonomic reliability assessment involves many emotional factors which are complicated; verification from different angles can better illustrate the effectiveness of the proposed method.

\section{Conclusions}

The reliability of man-machine system depends on the reliability of the people. In the innovative design process, the study of ergonomic reliability of the passenger car interface design can reduce the development cost and shorten the development cycle. Therefore, it is very important and practical to construct the ergonomic reliability assessment method of the interactive interface for passenger car. 
(1) On the basis of questionnaire survey and the classification of ergonomic reliability factors proposed by predecessors, a comprehensive evaluation index system of ergonomic reliability assessment of automotive cockpit interactive interface is established, in which 8 indexes are established in the criterion layer and 40 indexes are set in the index layer.

(2) In order to make full use of the complementarity between objective weighting method and subjective weighting method, a comprehensive weighting method based on Theil's entropy and MADM is proposed in this paper. It is the innovative in ergonomic reliability assessment that the weights of multilayer indexes are calculated conveniently based on Theil's entropy owning to its good decomposition characteristic. The objectivity and effectiveness of the ergonomic reliability assessment index of the automotive cockpit interface are improved.

(3) Based on the human cognitive reliability experiments, the validity and effectiveness of the ergonomic reliability assessment method can be verified from a different perspective. The analysis method of eye-tracking test is innovation used in the interface design of passenger car.

(4) Through the example verification, this method can not only scientifically evaluate ergonomic reliability of the automotive cockpit interface, but also put forward reasonable feedback according to the evaluation results of automotive cockpit interface design, which has strong practicality and is an effective ergonomic reliability assessment method for the interaction interface of passenger car.

\section{Data Availability}

The data used to support the findings of this study are available from the corresponding author upon request.

\section{Conflicts of Interest}

The authors declare that there are no conflicts of interest regarding the publication of this paper.

\section{Acknowledgments}

This work was partially supported by the National Natural Science Foundation of China (51905116), Science and Technology Program of Guangzhou, China (201904010463), Youth Innovative Talent Projects from Ordinary University of Guangdong Province (2019WQNCX099), Teaching Reform Project from Guangzhou University (09-18ZX0304), and Teaching Reform Project from Guangzhou University (09-18ZX0309).

\section{References}

[1] G. Morin, J.-M. Cardona, O. Prince, M. Pendola, and F. Perrin, "Reliability assessment of innovative designs in automotive industry," Structure and Infrastructure Engineering, vol. 5, no. 5, pp. 367-379, 2009.
[2] J. Mao, Q. Sun, and K. Gui, "Study on hesitant fuzzy multiattribute quality evaluation based on surface defect information of autobody panels," Mathematical Problems in Engineering, vol. 2020, pp. 1-10, 2020.

[3] R. Kai, T. Wencheng, W. Jian et al., Fatigue Reliability Analysis and Life Bench Test of Buffer Block in Car Damper, IEEE, Piscataway, NJ, USA, 2018.

[4] N. N. M. Nasir, S. Abdullah, S. S. K. Singh et al., "Evaluation of reliability-based fatigue strain data analysis for an automobile suspension under various road condition," International Journal of Integrated Engineering, vol. 10, no. 5SI, pp. 49-58, 2018.

[5] S. S. K. Singh, S. Abdullah, and N. A. N. Mohamed, "Reliability assessment for an automobile crankshaft under random loading," Jurnal Teknologi, vol. 78, no. 6-10, pp. 91-96, 2016.

[6] F. Abbasi, "Fuzzy reliability of an imprecise failure to start of an automobile using pseudo-parabolic fuzzy numbers," New Mathematics and Natural Computation, vol. 14, no. 03, pp. 323-341, 2018.

[7] Z. Liu, X. Liu, K. Wang et al., "GA-BP neural network-based strain prediction in full-scale static testing of wind turbine blades," Energies, vol. 12, no. 6, pp. 1-15, 2019.

[8] Z. Liu, Y.-F. Li, L.-P. He, Y.-J. Yang, and H.-Z. Huang, "A new fault tree analysis approach based on imprecise reliability model," Journal of Risk and Reliability, vol. 228, no. 4, pp. 371-381, 2014.

[9] D. Liao, S.-P. Zhu, B. Keshtegar, G. Qian, and Q. Wang, "Probabilistic framework for fatigue life assessment of notched components under size effects," International Journal of Mechanical Sciences, vol. 181, Article ID 105685, 2020.

[10] T. Koettermann, M. Grabert, S. Kempe et al., Bivariate Reliability Analysis of Driving Profiles in Automobile Fleets. Safety and Reliability: Methodology and Applications, pp. 327-334, CRC Press-Taylor \& Francis Group, Wroclaw, Poland, 2015.

[11] S. S. K. Singh, S. Abdullah, and N. A. N. Mohamed, "Reliability analysis and prediction for time to failure distribution of an automobile crankshaft," Eksploatacja I NiezawodnoscMaintenance and Reliability, vol. 17, no. 3, pp. 408-415, 2015.

[12] Y. I. Kwon, "Estimation of automobile components reliability using warranty repair data comprising early failures," Journal of Applied Reliability, vol. 19, no. 1, pp. 31-38, 2019.

[13] E. Lavrov, A. Tolbatov, N. Pasko et al., "Ergonomic reserves for improving reliability of data processing in distributed banking systems," in Proceedings of the 2017 2nd IEEE International Conference on Advanced Information and Communication Technologies-2017, pp. 79-82, Odisha, India, 2017.

[14] C. Brandl, A. Mertens, and C. M. Schlick, "Effect of sampling interval on the reliability of ergonomic analysis using the Ovako working posture analysing system (OWAS)," International Journal of Industrial Ergonomics, vol. 57, pp. 68-73, 2017.

[15] J. M. Rohani, A. J. Adeyemi, R. Abd Aziz et al., "The inter-rater and intra-rater reliability analysis of workplace ergonomic risk assessment," Jurnal Teknologi, vol. 80, no. 1, pp. 53-59, 2018.

[16] J. Zýka and I. Drahotský, "Methodology for assessing the impact of workplace ergonomic factors on airport security Screener's reliability and performance," Journal of Tourism and Services, vol. 10, no. 18, pp. 104-116, 2019.

[17] S.-P. Zhu, B. Keshtegar, S. Chakraborty, and N.-T. Trung, "Novel probabilistic model for searching most probable point 
in structural reliability analysis," Computer Methods in Applied Mechanics and Engineering, vol. 366, p. 113027, 2020.

[18] P. Hakkarainen, R. Ketola, and N. Nevala, "Reliability and usability of the ergonomic workplace method for assessing working environments," Theoretical Issues in Ergonomics Science, vol. 12, no. 4, pp. 367-378, 2011.

[19] F. Caputo, A. Greco, M. Fera, and R. Macchiaroli, "Workplace design ergonomic validation based on multiple human factors assessment methods and simulation," Production \& Manufacturing Research, vol. 7, no. 1, pp. 195-222, 2019.

[20] G. E. Raptis, C. Fidas, and N. Avouris, "Do game designers' decisions related to visual activities affect knowledge acquisition in cultural heritage games? an evaluation from a human cognitive processing perspective," Journal on Computing and Cultural Heritage, vol. 12, no. 1, pp. 1-25, 2019.

[21] A. Sievert, A. Witzki, and M. M. Nitzschner, "Reliability and validity of low temporal resolution eye tracking systems in cognitive performance tasks," International Journal of Mobile Human Computer Interaction, vol. 10, no. 1, pp. 40-51, 2018.

[22] B. Kowalik and M. Szpyrka, "An entropy-based car failure detection method based on data acquisition pipeline," Entropy, vol. 4, no. 21, p. 426, 2019.

[23] H. Nakayasu, M. Nakagawa, T. Miyoshi et al., "Human factor on driver and human cognitive reliability by driving simulator," in Proceedings of the 9th Pan-Pacific Conference on Ergonomics (PPCOE 2010), pp. 2011139-2011145, Kaohsiung, Taiwan, 2010.

[24] Z. Matuszak, M. Jaśkiewicz, D. Więckowski, and J. Stokłosa, "Remarks to the reliability assessment and to human actions especially car driver," MATEC Web of Conferences, vol. 134, Article ID 00036, 2017.

[25] M. Mahdy, "Weighted entropy measure: a new measure of information with ts properties in reliability theory and stochastic orders," Journal of Statistical Theory and Applications, vol. 17, no. 4, pp. 703-718, 2018.

[26] J. Vahedi, M. R. Ghasemi, and M. Miri, “An efficient entropybased method for reliability assessment by combining kriging meta-models," Periodica Polytechnica-Civil Engineering, vol. 63, no. 2, pp. 414-422, 2019.

[27] Q. Li, X. X. Meng, Y. B. Liu, and L. F. Pang, "Risk assessment of floor water inrush using entropy weight and variation coefficient model," Geotechnical and Geological Engineering, vol. 37, no. 3, pp. 1493-1501, 2018.

[28] P. Jiang, Y. Wang, C. Liu, Y.-C. Hu, and J. Xie, "Evaluating critical factors influencing the reliability of emergency logistics systems using multiple-attribute decision making," Symmetry, vol. 12, no. 7, p. 1115, 2020.

[29] S. Zhang, N.-B. Wang, H. Liu et al., "Approaches to multiple attribute decision making with the intuitionistic fuzzy information and their applications to user activities reliability evaluation," Proceedings of the National Academy of Sciences, India Section A: Physical Sciences, vol. 88, no. 1, pp. 89-94, 2018.

[30] H. Garg, "Generalized intuitionistic fuzzy entropy-based approach for solving multi-attribute decision-making problems with unknown attribute weights," Proceedings of the National Academy of Sciences, India Section A: Physical Sciences, vol. 89, no. 1, pp. 129-139, 2019.

[31] C.-H. Yeh, "A problem-based selection of multi-attribute decision-making methods," International Transactions in Operational Research, vol. 9, no. 2, pp. 169-181, 2002.

[32] L. Y. Y. L. Zheng Liu, "Comparisons of two non-probabilistic structural reliability analysis methods for aero-engine turbine disk," International Journal of Turbo \& Jet-Engines, vol. 3, no. 34, pp. 295-303, 2017.

[33] H. Kim, B. Liu, C. Y. Goh, S. Lee, and H. Myung, "Robust vehicle localization using entropy-weighted particle filterbased data fusion of vertical and road intensity information for a large scale urban area," IEEE Robotics and Automation Letters, vol. 2, no. 3, pp. 1518-1524, 2017.

[34] A. Karbassi Yazdi, T. Hanne, J. C. Osorio Gómez, and J. L. García Alcaraz, "Finding the best third-party logistics in the automobile industry: a hybrid approach," Mathematical Problems in Engineering, vol. 2018, Article ID 5251261, 19 pages, 2018.

[35] J. María Sarabia, V. Jordá, and L. Remuzgo, “The Theil indices in parametric families of income distributions-a short review," Review of Income and Wealth, vol. 63, no. 4, pp. 867-880, 2017.

[36] J. Miśkiewicz, "Globalization - entropy unification through the Theil index," Physica A: Statistical Mechanics and Its Applications, vol. 387, no. 26, pp. 6595-6604, 2008.

[37] R. T. D. Prabhakaran, B. J. C. Babu, and V. P. Agrawal, "Optimum selection of a composite product system using MADM approach," Materials and Manufacturing Processes, vol. 21, no. 8, pp. 883-891, 2006.

[38] X. Ze-Shui, Study on Methods for Multiple Attribute Decision Making under Some Situations, Southeast University, Nanjing, China, 2002.

[39] E. Hollnagel, Cognitive Reliability and Error Analysis Method, Elsevier, Horway, Germany, 1998.

[40] M. Abbassinia, O. Kalatpour, M. Motamedzade, A. Soltanian, and I. Mohammadfam, "Dynamic human error assessment in emergency using fuzzy bayesian CREAM," Journal of Research in Health Sciences, vol. 20, no. 1, p. e00468, 2020.

[41] S. P. Zhu, Q. Liu, J. Zhou, and Z. Y. Yu, "Fatigue reliability assessment of turbine discs under multi-source uncertainties," Fatigue \& Fracture of Engineering Materials \& Structures, vol. 41, no. 6, pp. 1291-1305, 2018.

[42] S.-P. Zhu, Q. Liu, W. Peng, and X.-C. Zhang, "Computational-experimental approaches for fatigue reliability assessment of turbine bladed disks," International Journal of Mechanical Sciences, vol. 142-143, pp. 502-517, 2018. 